\title{
Can a card mailing system help to reduce the waiting list at an alcohol problems clinic?
}

\author{
R. GoldBeCK, Research Registrar, Alcohol Problems Clinic, Royal Edinburgh \\ Hospital, 35 Morningside Park, Edinburgh EH10 5HF
}

Non-attendance at new patient clinics is a wellknown problem in psychiatry and particularly common in alcohol treatment units. Reported nonattendance rates in this field range from $12.3 \%$ (Addenbrooke \& Rathod, 1990) to 52\% (Wanberg \& Jones, 1973). A number of factors may contribute to this failure to attend including a long waiting time, lack of consent to the referral (e.g. by the GP), postal and administrative problems and the nature of the disorder itself. Hyslop \& Kershaw (1981) contacted patients who failed to attend an alcoholism referral clinic in an attempt to establish their reasons for non-attendance. Out of the 39 patients contacted 23 appeared to have good reasons for not attending while 16 gave poor reasons and refused the offer of a second appointment. Ways of increasing attendance at new patient clinics have included reduction of waiting time (Hyslop \& Kershaw, 1981) and telephone and written prompts prior to the appointment (Bourgoyne et al, 1983; Grover et al, 1983).

The Alcohol Problems Clinicis part of Edinburgh's main psychiatric hospital serving a population of approximately 600,000 and provides a regional service for problem drinkers. The unit receives between 12 and 15 new referrals a week and they are generally allocated to two new patient clinics. Patients are most commonly referred by their GPs but other sources include the general psychiatric service, general hospitals and self-referrals. The waiting time for a routine appointment is approximately six to eight weeks. Two slots are usually reserved at each new clinic for more urgent referrals. The non-attendance rate is high and new patient clinics are, therefore, routinely overbooked.

\section{The study}

The aim of the current study was to determine whether a card mailing system, whereby patients referred for a routine appointment were requested to confirm in advance whether or not they wished to attend for their appointment, could help to predict subsequent attendance and so allow clinic staff to re-allocate appointments in order to reduce the waiting list.

A card was sent to 102 consecutively referred patients waiting for a routine appointment, together with the notification of the date of their appointment. This would usually be several weeks in advance. Patients were requested to indicate on the card whether they wished to attend by ticking the appropriate box and then to return the card in a stamped addressed envelope to the Alcohol Problems Clinic. The card would also show the patient's name, the date of the appointment and the unit number. Records staff filled in these details beforehand and this allowed easy identification of the patient afterwards. The date on which the card arrived at the hospital was recorded. This was to determine how far in advance patients returned their cards, whether this related in any way to their subsequent attendance and how much 'warning time' clinic staff would have. Patients were requested to return the card as soon as possible and were also informed that should the staff not hear from them it would be assumed that they did not wish to attend and their appointment would be re-allocated. However, there was no deadline and at this stage no appointments were re-allocated.

\section{Findings}

One-hundred and two cards were sent out over a period of two months and 65 cards were returned. Although fifty-eight patients returned their cards indicating that they wished to attend only 36 of these people came for their appointment. Of the remaining 22 , two subsequently cancelled by phone. Twenty patients, therefore, did not attend in spite of indicating that they would. Four patients indicated on the card that they did not wish to attend and none of them came for an appointment. Three patients did not indicate on their cards whether or not they wished to attend. One attended, two did not.

Out of 37 patients who did not return their cards 31 subsequently failed to attend. Seven, however cancelled their appointment over the phone. One letter was returned by the post office and one appointment was cancelled by the GP as the patient had died. A total of 22 patients, therefore, did not return the card, did not cancel their appointments any other way and eventually failed to attend. Six patients who did not return their cards did in fact attend their appointment subsequently. One of these patients confirmed 
three days beforehand that she would attend and apologised for not returning the card.

In summary, of the 102 patients who received a card 43 eventually attended and 59 did not attend, giving an attendance rate of $42.2 \%$ (this compares with an attendance rate of $50 \%$ in 102 previous consecutive referrals which is a non-significant difference, $\chi^{2} 1.26$ ). The attendance rate in patients who returned the card is (not surprisingly) significantly higher than in those who did not return the card $\left(\chi^{2}=16.029, P<0.001\right)$.

In 62 out of 65 patients who returned the card the time between reception of the card at the hospital and the appointment could be calculated. This ranged from four to 39 days with a mean of 23.7 days. In only six cases less than ten days remained. There was no significant relationship between how early the card was sent back and subsequent attendance.

\section{Comment}

Asking patients routinely referred to a new patient clinic to return a card to indicate their intention to attend did not influence the overall attendance rate as compared with a group of patients who did not receive a card. The non-attendance rate in this sample $(57.2 \%)$ is higher than reported figures in the literature. This may be due to only routine referrals being included with patients having to wait several weeks for their appointments. Previous studies have shown that shorter waiting times lead to better attendance and thus inclusion of emergency referrals might have given a lower non-attendance rate.

Sixty-two per cent of patients who returned the card and stated that they wished to attend subsequently came to their appointments. The remaining $38 \%$ failed to attend. This may be because their intention to attend either changed (e. g. because the original crisis was over or help had been found elsewhere) or because they were unable to attend due to the nature of their disorder (e.g. intoxication, poor physical health, admittance to hospital elsewhere etc.). A small proportion of patients who returned the card indicated that they did not wish to attend $(6.2 \%)$. This again may indicate that the acute crisis was over or that the patient was ambivalent at the time of the original referral or even put under pressure. One patient, in fact, wrote and explained that he did not really wish to stop drinking and felt that the appointment should rather be given to somebody else. Another patient wrote to say that she was back on her feet and had become involved again with AA.

Although the majority of patients who did not return the card $(83.8 \%)$ failed to attend, a small but significant proportion (16.2\%) attended despite not sending back the card. The reasons for their failure to return the card are unclear. One patient phoned three days before her appointment to confirm; the rest either did not bother or may have forgotten. A mailing problem might also be an explanation. Most cards were returned well in advance of the appointment date with only six cards arriving less than ten days beforehand.

\section{Conclusions}

It seems possible that the appointments of patients who do not return their cards by ten days prior to the new clinic date could be re-allocated to other patients on the waiting list or urgent referrals. Patients could be informed that they must confirm their appointment at least 14 days prior to the appointment date or else they will forfeit their appointment. Had the above practice been employed as part of the present study then double bookings would have only occurred on six occasions. The described card system could contribute to a reduction in the waiting time for new appointments and/or free more slots for urgent referrals. Its usefulness would depend on a sufficiently long waiting time for new appointments in order to allow records staff to re-allocate appointments not taken up. It could come into operation whenever the waiting list exceeds three to four weeks.

The Alcohol Problems Clinic is planning to adopt the card system on a routine basis in the near future. It will then be possible to make an assessment of its effects on the waiting list.

\section{References}

AdDENBROOKE, W. M. \& RATHOd, N. H. (1990) Relationship between waiting time and retention in treatment amongst substance abusers. Drug and Alcohol Dependence, 26, 255-264.

Bourgoyne, R. V., Acosta, F. X. \& Yamamoto, J. (1983) Telephone prompting to increase attendance at a psychiatric out-patient clinic. American Journal of Psychiatry, 140, 345-347.

Grover, S., Gagnon, G., Flegel, D. M. \& Hoey, J. R. (1983) Improving appointment keeping by patients new to a hospital medical clinic with telephone or mailed reminders. Canadian Medical Association Journal, 129, 1101-1103.

Hyslop, A. \& Kershaw, P. (1981) Non-attenders at an alcoholism referral clinic. Health Bulletin, 39, 314-319.

WANBERG, K. W. \& JONES, E. (1973) Initial contact and admission of persons requesting treatment for alcohol problems. British Journal of Addiction, 68, 281-285.

A full list of references is available from the author on request. 